\title{
LOW-COST SENSORS FOR AIR QUALITY MONITORING - THE CURRENT STATE OF THE TECHNOLOGY AND A USE OVERVIEW
}

\begin{abstract}
In recent years the monitoring of air quality using cheap sensors has become an interesting alternative to conventional analytical techniques. Apart from vast price differences conventional techniques need to be performed by the trained personnel of commercial or research laboratories. Sensors capable of measuring dust, ozone, nitrogen and sulphur oxides, or other air pollutants are relatively simple electronic devices, which are comparable in size to a mobile phone. They provide the general public with the possibility to monitor air quality which can contribute to various projects that differ in regional scale, commercial funding or community-base. In connection with the low price of sensors arises the question of the quality of measured data. This issue is addressed by a number of studies focused on comparing the sensor data with the data of reference measurements. Sensory measurement is influenced by the monitored analyte, type and design of the particular sensor, as well as by the measurement conditions. Currently sensor networks serve as an additional source of information to the network of air quality monitoring stations, where the density of the network provides concentration trends in the area that may exceed specific measured values of pollutant concentrations and low uncertainty of reference measurements. The constant development of all types of sensors is leading to improvements and the difference in data quality between sensors and conventional monitoring techniques may be reduced.
\end{abstract}

Keywords: air quality measurements, photoionisation detector, electrochemical sensor, fine particle monitor

\section{Introduction}

The idea of air quality monitoring provided by sensor technology as an inexpensive alternative to professional equipment is very attractive, even if the lower quality of the provided data is taken into account. Sensor technology has been developing for the last 25 years; over the course of the last 10 years their use has increased significantly, as is shown in Figure 1. Due to miniaturization and low energy consumption sensor units are used in personal portable devices to assess human exposure to air pollutants [1,2]. They are comparable in size to a larger mobile phone. Easy installation and maintenance-free operation allows for measurements in remote and/or inaccessible areas [3, 4], showing that the use of expensive professional instruments is not always necessary (or even possible) for answering some questions of air quality [5]. These devices also have the distinct advantage of a stand-alone battery operation in combination with photovoltaic charging. An additional advantage of the sensors is the short sampling intervals for the time-resolved data (units up to the first tens of minutes [6]) that help with understanding the dynamics and development

\footnotetext{
${ }^{1}$ Institute of Environmental Technology, CEET, VSB-Technical University of Ostrava, 17. listopadu 2172/15, 70800 Ostrava, Czech Republic

*Corresponding author: pavel.bucek@vsb.cz
} 
of pollutant concentrations in the monitored area. Large-scale deployment of sensor networks leads to good spatial and temporal resolution of the air pollution monitoring [7-10]. Thus, we know when, where and how the pollutants' concentrations change, and from this the causes of these episodes can be investigated (e.g. the diurnal impact of traffic, indoor air filtration [11], street cleaning using leaf blowers [12]). Another area for the use of sensor units are projects for air quality monitoring and display stations for the general public, as commercial projects, or as user-performed in the field of citizen science.

Current scientific and technological goals are a comparison of sensor-produced data quality to reference instruments data, verification of metrological parameters of individual sensors and a definition of sensor technology limitations, scopes of use and measurement limits.

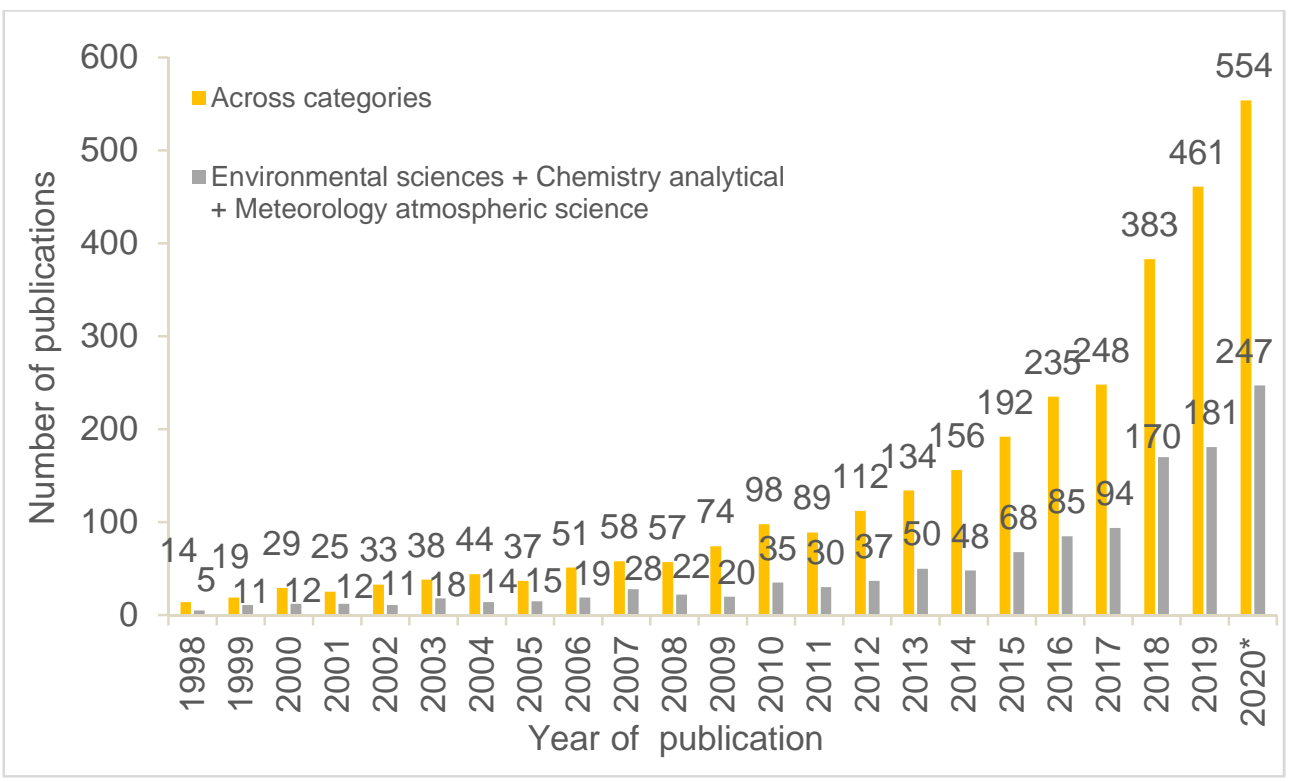

Fig. 1. Number of publications indexed by Web of Science for the topic. Search parameters: keywords Air quality and sensors, no year limitation applied. Applied result filter: Document type - Article, across categories, further narrowed down to relevant categories - Chemistry analytical, Environmental sciences and Meteorology, atmospheric science; ${ }^{*}$ - Data up to 30th November 2020, articles planned for publication in 2021 included

\section{Sensors and monitored parameters}

In this article we use the term "sensor" for a single measuring element and the term "sensor unit" for a device that combines one or more sensors and electronics used for data processing, storage or transfer to a remote database.

\section{Particle (dust) sensors}

Currently, most of the small dust monitoring devices available on the market use the optical method - a scattering of light or laser radiation on particles. In the majority of these devices, the distribution curve is programmed to group particles by size, usually into groups 
up to $1 \mu \mathrm{m}, 2.5 \mu \mathrm{m}$ and up to $10 \mu \mathrm{m}$. An example of the class is the Plantower dust sensor, currently in its 7th generation, that is built into a box of outer dimensions $48 \times 32 \times 12 \mathrm{~mm}$ and powered from a USB interface. In Chinese e-shops a single unit is priced around 15 USD and bulk order discounts are offered. Competing units of similar design are offered in the price range from 20 to hundreds of USD / EUR (e.g., Alphasense, OPC-N2) [13].

\section{Optical, electrochemical and semiconductor gas sensors}

In optical gas sensors, non-dispersive infrared radiation absorption (NDIR) is used as the working principle. The radiation of specific wavelengths absorbed by gas molecules is used for the detection of carbon dioxide, gaseous substituted and unsubstituted hydrocarbons (methane-butane, refrigerants, acetone) and sulphur hexafluoride $\left(\mathrm{SF}_{6}\right)$ [14]. Optical sensors are used for most of these substances in industrial plants, where they monitor possible leaks and thus increase the safety of the workers and production facilities. Refrigerants based on halogenated hydrocarbons are ozone depleting compounds, among which sulphur hexafluoride is one of the most powerful [15].

Table 1

Comparison of electrochemical sensors from manufacturers supplying sensors both standalone for public and for third-party devices. Other sensor types sensing the same analytes have been added for orientation [16, 17]

\begin{tabular}{|c|c|c|c|c|c|c|}
\hline Manufacturer & \multicolumn{3}{|c|}{ Environmental sensors } & \multicolumn{3}{|c|}{ Alphasense } \\
\hline Detected substance & $\begin{array}{l}\text { Range } \\
\text { [ppm] }\end{array}$ & $\begin{array}{c}\text { Sensitivity } \\
\text { [ppm] }\end{array}$ & $\begin{array}{c}\text { Overgas limit } \\
{[\mathrm{ppm}]}\end{array}$ & $\begin{array}{l}\text { Range } \\
\text { [ppm] }\end{array}$ & $\begin{array}{c}\begin{array}{c}\text { Sensitivity } \\
\text { [ppm] }\end{array} \\
\end{array}$ & $\begin{array}{c}\text { Overgas } \\
\text { limit [ppm] }\end{array}$ \\
\hline Ammonia & $0-100$ & 0.1 & 200 & $0-100$ & 0.3 & 200 \\
\hline Chlorine & $0-20$ & 0.1 & 250 & $0-20$ & 0.02 & 60 \\
\hline Ethylene oxide & $0-20$ & 0.1 & 100 & $0-100$ & 0.1 & 200 \\
\hline Formaldehyde & $0-30$ & 0.01 & 34 & \multicolumn{3}{|c|}{ Not produced } \\
\hline Glutaraldehyde & $0-20$ & 0.01 & 20 & \multicolumn{3}{|c|}{ Not produced } \\
\hline Sulfane & $0-50$ & 0.1 & 500 & $0-2000^{*}$ & 0.5 & 10000 \\
\hline Nitric oxide & $0-100$ & 0.1 & 1500 & $0-20$ & 0.1 & 50 \\
\hline Nitrogen dioxide & $0-20$ & 0.1 & 200 & $0-20$ & 0.02 & 50 \\
\hline Ozone & $0-2$ & 0.01 & 5 & $0-20$ & 0.5 & 50 \\
\hline Sulphur dioxide & $0-20$ & 0.1 & 100 & $0-2000^{*}$ & 1,5 & 10000 \\
\hline Carbon oxide & $0-300$ & 1 & 1000 & $0-10000^{*}$ & 5 & 100000 \\
\hline Carbon dioxide (NDIR) & \multicolumn{3}{|c|}{ Not produced } & $0-2000^{*}$ & 10 & None \\
\hline Methane (NDIR) & \multicolumn{3}{|c|}{ Not produced } & $0-100 \%^{*}$ & $1 \%$ & None \\
\hline Carbon oxide (MOS) & \multicolumn{3}{|c|}{ Not produced } & $5-500$ & 2 & None \\
\hline Sulfane (MOS) & \multicolumn{3}{|c|}{ Not produced } & $1-100$ & 1 & None \\
\hline
\end{tabular}

* More variants available, according to expected use Overgas limit $=$ sensed concentration, after which the sensor signal reaches background within sampling cycle and continues operation unaffected

Electrochemical sensors detect gases that diffuse from the environment through a gas-permeable membrane. Inside the sensor cell an electric field is applied to the electrolyte, forcing gas molecules to migrate to the working electrode and an electron exchange reaction (oxidation or reduction) occurs. On the counter-electrode, opposite reaction takes place to balance electrons in redox reaction pair and a change in the current is detected. The selectivity of the sensor is tuned by electrolyte composition, polarity and intensity of the electric field that together influence the migration of analytes [7, 18]. Electrochemical sensors were originally used mainly for leakage detection in production 
facilities. However, over time their sensitivity and selectivity have greatly improved so that nowadays they are also utilized for air quality monitoring [7].

The detection principle of semiconductor sensors is based on changes of electrical resistance when sensed analyte comes into contact with the semiconductor surface layer. The most common group of materials used are various metal oxides and the group is named accordingly as Metal Oxide Sensors (MOS). In general there are two basic types of MOS according to the nature of the detection mechanism: type $\mathrm{n}$ changes the resistance in the presence of reducing gases and type $\mathrm{p}$ changes resistance after coming into contact with oxidizing gases. Selectivity and specificity of the sensors are influenced by a suitable combination of the primary material of the semiconductor, grain (structure unit) size, dopants or possible impurities and operating temperature [19-22]. Along with the development of nanomaterials and associated surface treatment methods [23] ever lower detection limits are being achieved and measuring ranges of semiconductor sensors reach the upper limits of the legal concentrations for some gaseous air pollutants (sulfane, carbon monoxide, etc.) [19]. A comparison of the measuring ranges for volatile organic compounds is shown in Figure 2.

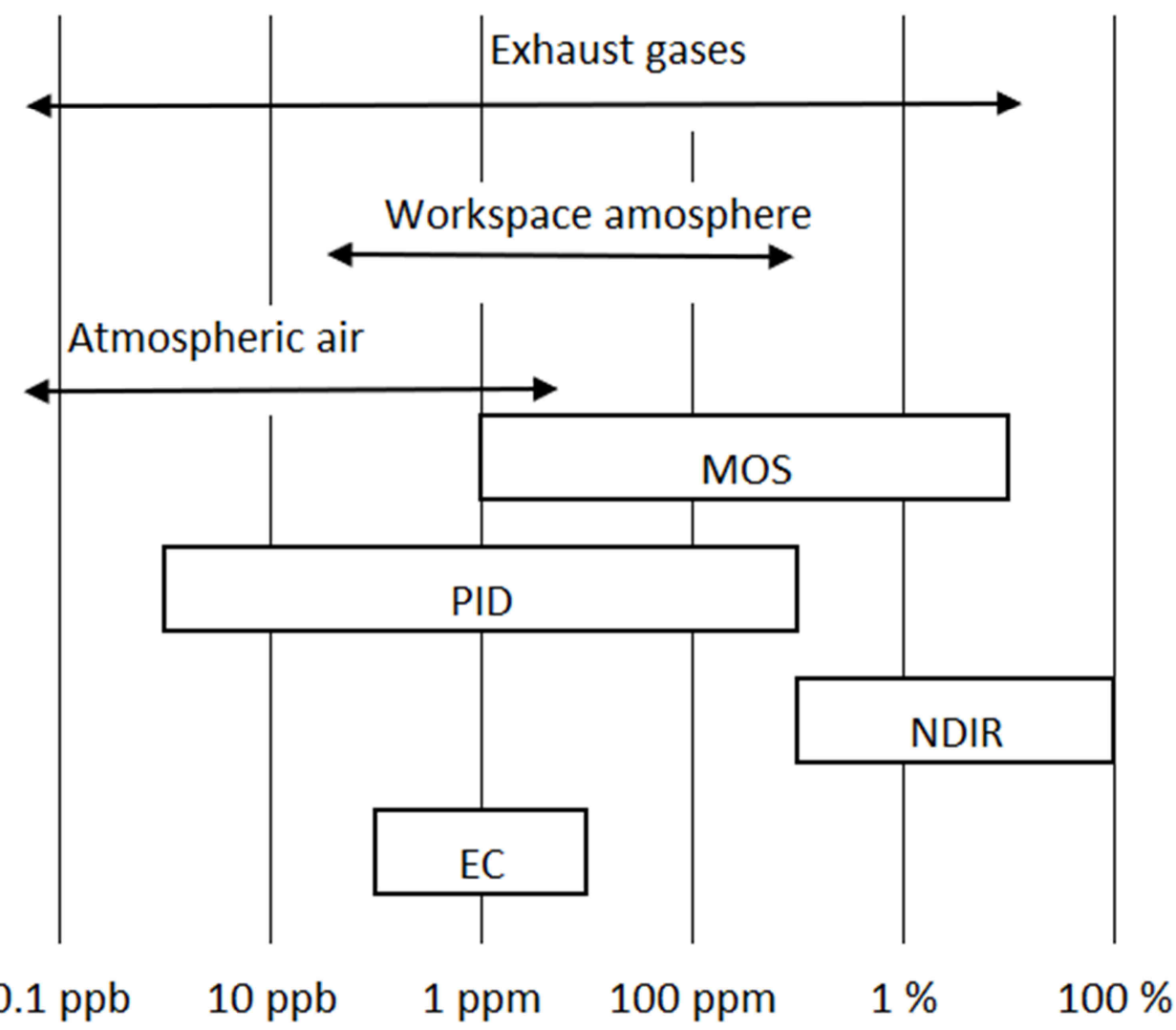

Fig. 2. Comparison of measuring range of sensors for volatile organic compounds (VOCs), their sources and occurrence in the environment (adapted from [18]) 


\section{Photoionisation sensors (PID)}

In photoionisation detectors a hard-UV lamp irradiates molecules in the ionization chamber. If the molecule's ionization potential is lower than the energy of used radiation, ions and electrons are formed from neutral molecules. In the detector's electric field charged particles are attracted to electrodes and they generate a current proportional to the concentration. The usable ionization energy of a particular lamp type is determined by the lamp's gas filling and the material of the lamp window for emitting UV radiation. In practice detectors use ionization energies of approximately $10 \mathrm{eV}$, the exact values depend on the particular design of a specific lamp type. In order to avoid interference of radiation with solid particles, water droplets, or aerosol of detectable compounds, the ionization chambers are separated by gas-permeable membranes.

Technically, the photoionisation sensor consists of several changeable modules that have different lifetimes. Figure 3 shows the whole Alphasense PID sensor and individual modules. The sensor body contains electronics for signal amplification and transfer, connecting pins for ionization chamber collector circuit and connections for the discharge lamp. According to manufacturers (e.g., Alphasense, IonScience), the lifespan of the body is 5 years. Lamps and cells are considered consumables with an expected operating time of 5000 hours or 24 months [24]. Ionization energies of commonly used lamps are 9.8 and $10.5 \mathrm{eV}$, the $11.7 \mathrm{eV}$ variant is offered only by some manufacturers. The operating time of $11.7 \mathrm{eV}$ discharge lamps is very limited in all types of devices. There are two reasons for such a short lifetime: the first is the material of their windows - lithium fluoride that absorbs moisture, which then degrades its optical properties. The second reason is a process of solarisation - a change of window colour by deposition caused on the material surface by incident UV radiation. Sensors equipped with the $11.7 \mathrm{eV}$ lamp are not used for long-term measurements, as the aforementioned reasons limit the lifetime to about a month of intermittent operation or up to 25 hours in continuous operation [25-27].

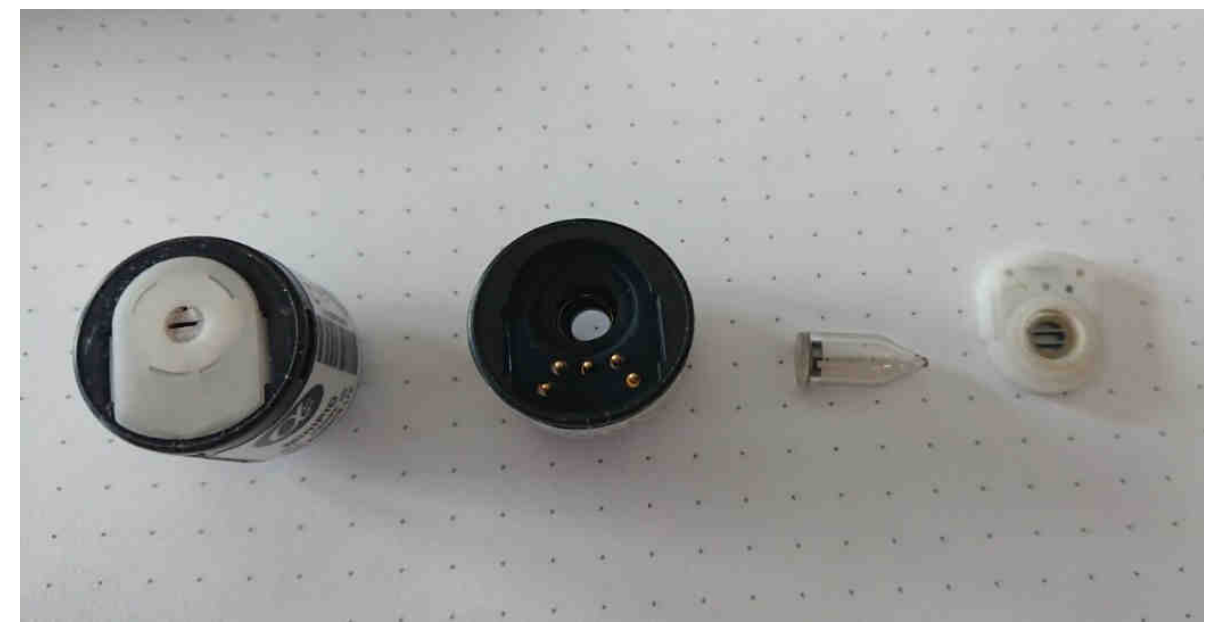

Fig. 3. Alphasense photoionisation sensor; Left to right: completed sensor, sensor body with electronics and contacts, discharge lamp and measuring cell with visible electrodes; Background point pitch $5 \mathrm{~mm}$ 


\section{Devices}

Due to their design all of the above explained sensor types provide output as electrical voltage in millivolts. This is a collected signal that must be further processed. The simplest processing devices are integrated circuits for single sensor signal amplification and forwarding. Signals from various sensors can be collected and processed by Arduino-like processors or applications running on Raspberry or similar mini computers [28].

Sensor measurement units in a basic setup contain a dust sensor accompanied with temperature and humidity sensors. Depending on the intended use and size, other gas sensors may be added, some traffic monitoring projects also add a noise sensor [29].

There are discrepancies concerning price in the recommended or expected limits for sensor units. According to a study by Malings et al. [30], equipment for personal use should not exceed 250 USD and sensor units intended for long-term professional measurements should not exceed 5000 USD. Other projects state the price limit at 2000 USD per analyte for both types of units [31].

\section{Field use}

Outside science and research fields of interest the use of sensor based technology covers a wide range from narrow-spectrum professional detectors for production facilities, across commercial indoor and outdoor air quality sensor units [32,33], to do-it-yourself air quality sensing devices that use a unified design and data processing apps within a framework of citizen science projects [34]. Examples of the first group are instruments for the detection of volatile organic compounds (VOCs), mercury or operational gas leaks (both portable and fixed, e.g., by IonScience, Ltd.) [35], using photoionisation detection sensors [36]. Examples of the two latter groups will be given later in next section.

Taking advantage of the low price of the sensor technology, sensor network projects have been developing in recent years. Certain areas are covered with a dense network of sensing units to monitor pollutant concentrations over time. From such datasets, maps and visualizations are made to show the temporally and spatially differentiated development of air pollution [37, 38]. Small portable devices are used to monitor pollutant exposure in individuals carrying them [2].

\section{Project examples}

In this section we present projects funded through various sources, focusing on the use of sensor units for air quality monitoring. Projects that focus mainly on development of sensing materials, processing of data from aggregated air quality databases, or other applications to assess personal exposure or protect public health regardless of data collection are intentionally omitted.

\section{Publicly funded projects}

Currently such projects are distinguished by the use of closed networks of private design. In most cases the general public is not allowed to join projects by purchasing and deploying sensor units. For some of the projects the data and results were published, some remain accessible only to participating institutions. The comments and conclusions are related to the results available to the general public up to 30th November 2020. 
Bettair (https://bettaircities.com/): Project of air quality monitoring of large ports surroundings in big cities (initially Barcelona and Porto, intended expansion). Data from monitoring sensor networks are used for visualisation and modelling of pollution possibly originating in ports (dust, exhaust gases). Stationary and portable unit types are used. Stationary units always contain dust, temperature and humidity sensors that can be accompanied by gas sensors $\left(\mathrm{NO}_{2}, \mathrm{NO}, \mathrm{CO}, \mathrm{O}_{3}, \mathrm{SO}_{2}, \mathrm{H}_{2} \mathrm{~S}\right)$. In portable units, the selection of accompanying gas sensors is reduced to a maximum of 3 due to their smaller size. The units are interconnected by various wireless connections. Among partners of the project there are telecommunication companies and hardware developers, probably interested in testing features for the Internet of Things platform. There are no public data available apart from location specifications (e.g., Girona [39]) and project presentation [40].

AirVeraCity (https://airveracity.com/): Lausanne-based air quality project, aimed at reducing the number of sensor units in the network. The units are located on the vehicles of public transport circulating through the city, 20 circulating units should be equivalent to 500 stationary units. Air quality data cover concentration of $\mathrm{NO}_{2}, \mathrm{CO}, \mathrm{O}_{3}, \mathrm{SO}_{2}, \mathrm{H}_{2} \mathrm{~S}, \mathrm{VOC}$ a LDSA (Lung-Deposited Surface Area, calculated parameter). The project plan includes the use of smaller sensor units in addition to large ones. Smaller units should be portable for personal use or mounted to city shared bicycles.

CAIRSENSE (https://www.epa.gov/air-research/community-air-sensor-networkcairsense-project-lower-cost-continuous-ambient-monitoring): US EPA project active in years 2013-2014 in the surroundings of Atlanta city. According to the project presentation expansion to Denver and other distant cities was planned. In the project framework gases and particles were monitored using several sensors available at the time $\left(\mathrm{NO}, \mathrm{NO}_{2}, \mathrm{CO}, \mathrm{O}_{3}\right.$, $\mathrm{SO}_{2}, \mathrm{H}_{2} \mathrm{~S}$, VOC semiconductor and electrochemical sensors). Sensor units were originally deployed in the proximity of a reference monitoring station and air quality data were compared. Comparison of the data is presented on the websites, project presentation and peer reviewed article are also available [31].

\section{Commercial projects}

For this overview projects are considered commercial if the public user can engage by purchasing and simply starting to use the equipment. No knowledge of air quality monitoring is required. In general units contain the same sensors built in to better-looking housing. The devices are connected to databases storing data that are accessible to users from various platforms (mobile applications, etc.). In addition, some products contain screens to display calculated air quality indexes and other information (e.g., recommendations for physical activity, ventilation).

Air Quality Egg (https://airqualityegg.com/home): Offering exterior and interior units, configurable: device always contains temperature, pressure and humidity sensors, possible extension with dust sensor and gas sensors ( $\left.\mathrm{NO}, \mathrm{NO}_{2}, \mathrm{CO}, \mathrm{CO}_{2}, \mathrm{O}_{3}, \mathrm{SO}_{2}, \mathrm{H}_{2} \mathrm{~S}, \mathrm{VOC}\right)$. Price ranges between 220 and 350 USD according to configuration.

AirBeam (https://www.habitatmap.org/airbeam): Portable (wearable) units, containing dust, humidity and temperature sensors. Project uses also other units that are able connect to network and transfer data. Visualization interface was used in other air quality monitoring projects (e.g. Citi-Sense 2012-2016) and the older data sets are accessible there. Retail price of the unit is 250 USD.

Air Node Visual (https://www.iqair.com/air-quality-monitors/airvisual-pro): Indoor monitoring unit contains dust, $\mathrm{CO}_{2}$, temperature and humidity sensors. Device 
communicates with central database, sending current air quality data and receiving processed information. Retail price 269 EUR.

Speck (https://www.specksensor.com/learn/particles): Indoor dust sensor unit, communicates with database which is accessible for users after product registration. Retail price 150 USD.

\section{Community-based projects}

For our definition community-based projects are characterized by an effort to minimize price in exchange for the participants' time required for assembly and operation of the measuring devices. Databases of measured data are usually public and accessible after registration, some are interconnected. Volunteer groups of some projects, for example, organise software / firmware uploads and initial settings of participants' sensor units built according to unified public instructions.

OK Lab Stuttgart (https://luftdaten.info/): OK stands for Open Knowledge, initiative of independent groups of programmers that manage the software of the sensor units, database and visualization application. Citizen science based project uses data from homemade units based on Plantower dust sensor, instructions and parts list for unit assembly are published at project website.

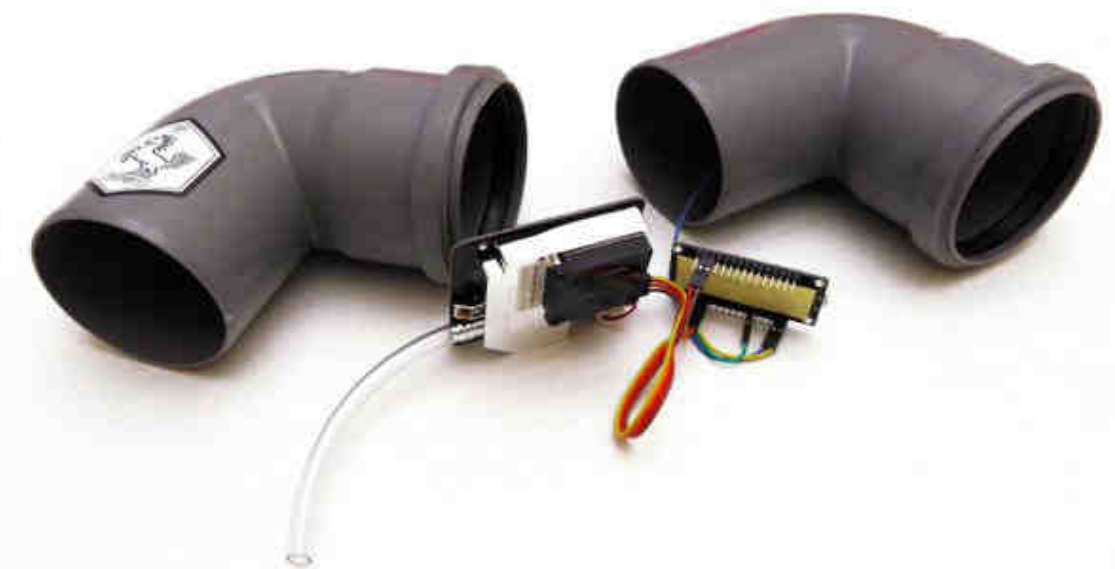

Fig. 4. Picture instructions on dust sensing device assembly, parts list and hints for purchase included. Drain pipe bends are protective casing. Source: luftdaten.info

\section{Discussion}

Opinions on air quality monitoring using sensors range from uncritically optimistic to rejecting the results as inapplicable. Supporters of the former are mostly tech and data enthusiasts, the latter are backed by many analytical chemists and air quality monitoring experts. Questions on the data quality of sensor measurement are not only addressed by sensor research teams, but there are specialised workplaces and commissions specifically for sensor verification. For example, within California's South Coast Air Quality Management District there is a group of researchers testing and verifying sensor units - the Air Quality Sensor Performance Evaluation Center. Its website [13] contains a section 
where a comparison of a large number of dust meters and gas sensors is presented together with correlation coefficients and reports of the laboratory and field tests. Besides correlation to reference methods (where possible) and measurement reproducibility obtained by deploying several same or similar sensors, there are not many methods for sensor validation. Efforts to target and describe possible limitations in terms of influencing precision and selectivity/sensitivity of sensor measurements are processing [41, 42]. In comparing sensor-monitoring studies we do not present correlation coefficients, because each group is aiming its research at different targets. This corresponds to the different correlation calculations and conclusions on the data applicability.

Concerning the measurement of concentrations of suspended particles by dust sensors, some studies drew different conclusions from comparisons with reference methods (gravimetric and optical) - both higher [30, 43, 44] and lower [10] averages are reported. A difference seems to originate between the output of sole sensor measurement and sensor units with integrated data processing algorithms. In such cases, applied corrections may result in significantly lower concentrations compared to the reference gravimetric method [10]. Another study conducted by the same group points to the problematic placement of the tested devices - sensor units and reference optical dust meters were placed near each other at several levels, which led to mutual shielding and reduction of measured values at particular heights [45]. Other studies attributed these differences to humidity and temperature effects on the sensor's simple optics, which consist of a single source and a single radiation detector [46]. Improved correlation was reported in studies conducting measurements in areas of variable weather that applied corrections for temperature, humidity, and even the dew point $[8,43,47,48]$. Measurements in dry and warm areas led to conclusions that the humidity effect was insignificant and the correction unnecessary [49]. Attempts to calibrate sensors with reference materials have also been made [50]. In the field of sensor development there is a clear effort to suppress or quantify the environment interferences by both computing algorithms [51] and improvements of the sensor body design [52].

Gas sensors represent a large combinatorial set with many variables: up to 6 analytes $\left(\mathrm{CO}, \mathrm{CO}_{2}, \mathrm{NO}, \mathrm{NO}_{2}, \mathrm{O}_{3}, \mathrm{SO}_{2}\right)$ are sensed in practice using sensors based on 3 different principles (NDIR, EC, MOC). In addition, some of the sensors are capable of sensing multiple analytes at once and some analytes may be measured by several different sensors. Moreover, mutual interferences and possible influence of meteorological conditions have to be accounted for. Basic simultaneously monitored parameters are temperature and humidity, possibly accompanied with pressure, wind strength and direction and even solar radiation intensity. Conclusions in most cases are that sensors are applicable with drawbacks and issues that should be dealt with. Further, we present several studies focusing on air quality monitoring using gas sensors and reference methods, their conditions and findings about results and data (dis)agreement.

Bauerova, 2020 [43]: The study summarises the experience from an annual experimental measurement with a set of electrochemical sensors for inorganic gases $(\mathrm{CO}$, $\mathrm{NO}_{2}, \mathrm{O}_{3}, \mathrm{SO}_{2}$ ) manufactured by Cairpol (France) and two types of dust sensors. The results were compared with reference methods, except for the carbon monoxide measurements. Combined sensors for $\mathrm{NO}_{2}$ and ozone performed very well in accordance with reference measurements. Other sensors had poor correlations, sometimes even among pairs of the same sensor type. Correlations were generally better in all sensor types in warmer months of the year when compared to winter. A very important conclusion of the study is that the 
limit of the sensors' practical service life was achieved. After about 11 months of continuous operation all of the tested sensors drifted to unrealistically high and stable measured signals. Comparison of Plantower and Alphasense dust sensors with the reference method showed a good correlation for both types. Alphasense dust sensors, in addition to a shorter life, showed a very high number of outlying (unrealistically high) measurement results.

Clougherty, 2017 [53]: Year-round measurements in a moderate climate zone with four seasons (New York). Units sensing $\mathrm{NO}_{\mathrm{x}}, \mathrm{O}_{3}$ and $\mathrm{SO}_{2}$ were deployed in 155 locations in order to identify or confirm their sources. Results from units located near air quality monitoring station were compared with reference methods, other units were checked using multi-day sampling campaigns of passive samplers. Models were compiled from the results and data series. The following findings could be concluded: not all units measured all analytes, sulfur dioxide results correlated with the reference measurement very well, for nitrogen oxides the correlation was lower but acceptable. Ozone results were not evaluated at all, probably due to mutual interferences of measured gases that weren't corrected for finally. Those interferences are described in next paragraph, as that study contains their detailed explanation and corrections. The individual measurements of several units at the same locations did not differ significantly. The sum of measured concentrations correlated very well with the values of passive samplers at all locations.

Jiao, 2016 [31]: Comparison of reference methods and data of 6 sensor units located along with air quality monitoring station. Parallel measurements were performed for 8 months (August to May) as a part of sensor validation and communication testing for a larger project, in southeastern United States (Georgia, warmer climate without freezing winters). Gases measured: $\mathrm{CO}, \mathrm{NO}, \mathrm{NO}_{2}, \mathrm{O}_{3}$ a $\mathrm{SO}_{2}$, some with several different sensors, not all units measured all gases. Conclusions: The $\mathrm{CO}$ semiconductor sensor did not respond within the required range at all, the electrochemical $\mathrm{CO}$ sensor's correlation was acceptable after the correction function was applied for the number of running days (or loss of sensitivity). Only one of the three different types of $\mathrm{NO}_{2}$ sensors produced a valid output. A combined electrochemical sensor sensing $\mathrm{NO}_{2}$ and $\mathrm{O}_{3}$, and a complex correction function of mutual gas interferences was required. The correction function was based on the data of the MOS ozone sensor (stand-alone, excellent correlation with reference method), correlation significantly improved after its introduction. In general, electrochemical sensors correlated worse with the reference methods than semiconductor sensors and all sensor field measurements correlated worse than laboratory measurements. Introduction of temperature-based corrections functions led to improved correlation. Spatial and temporal developments of gas concentrations were in good agreement with the reference methods.

Mead, 2013 [7]: Testing of portable (wearable) gas sensor units $\left(\mathrm{CO}, \mathrm{NO}, \mathrm{NO}_{2}\right)$ by multi-day concurrent measurements both in field and in laboratory. Very good correlations with reference methods were obtained at constant temperature measurements indoors and good agreement of temporal and spatial resolution for all three parameters while units were worn and moving. Significant improvement of correlations was revealed after the introduction of temperature and absolute (not relative) humidity based correction function. Very good long-term stability of sensory measurements was observed for a further 6 months. Sensor units were designed and assembled in-house and developed in collaboration with experts from the company Alphasense.

Spinelle, 2015 [41, 42]: Field tests of metrological parameters for sensor verification organised by the European Commission according to EURAMET methodology [54] (some 
of the authors of the study participated in the methodology proposal and verification). A total amount of 22 sensors (various analytes $\mathrm{CO}, \mathrm{CO}_{2}, \mathrm{NO}_{\mathrm{x}}, \mathrm{O}_{3}, \mathrm{SO}_{2}$ ) were tested in clusters of individual sensors. The sensors were tested in the proximity of reference instruments, exposed to calibration gases of variable composition under monitored conditions and meteorological parameters recorded. Measurement data were divided into random sets and analysed by linear regression, multidimensional regression, and artificial neural networks (several different setups). Calibration relationships and mutual interferences were obtained for different sensor detection principles and analytes. In the conclusions of the study, the relationships and limitations discovered under the measurement conditions are analysed in detail. In this study, field measurements were performed from January to July, but the calibration sets included only data from March to July. This winter data cut off and findings of other studies [43, 53] may and suggest problems connected to operation in low temperature, although to our knowledge, no definite conclusions were published on such a topic so far. In our opinion every potential user of sensor technology for measuring inorganic gases should get acquainted with the conclusions of this study.

The field of photoionisation sensors is of growing interest, as confirmed by some manufacturers of VOC detectors. New generations of their devices for operational leak and working environment monitoring already use photoionisation sensors instead of electrochemical and semiconductor detectors [55-57]. The greatest downside of photoionisation detectors still remains - it is impossible to identify individual detected substances. The identification of individual VOCs after photoionisation detection is possible today only after prior separation, just as it was four decades ago [58], despite all efforts in data processing and instrumentation development [59]. Portable handheld devices operating on a chromatographic principle with photoionisation detection are both available commercially $[60,61]$ and further researched and developed [62].

\section{Conclusion}

Scientists and technology developers even in rich industrial countries are aware that the number of operative air quality monitoring reference devices is limited, especially due to its prices. Obtaining more information on air quality has been a task followed by many for a long time. Even though the data are additional and supplemental, not equally precise to reference techniques. Alternatives to them were developed before use of sensor technology: first with passive samplers (suitable for sampling VOCs or inorganic gases from air, analysed after desorption by chromatographic methods) and later with the analysis of high-resolution satellite pictures. Methods of advanced data processing of visible and/or infrared spectrum composition were introduced in the first decade of 21 st century, and have become established and are undergoing continuous development [63-65]. Likewise, sensory measurements can currently be seen as a suitable source of additional data that would not be possible using the existing network of reference stations.

Quality of the data from sensory measurements vary depending on analyte(s), operating conditions and often on the individual production piece. There are also verifiable changes in the produced signals over the service life of sensors or issues with maintaining a predefined setting for real measurement, respectively. Checking of the sensors, either during production or during use, is necessary not only for these reasons. There is a great risk of malfunction, especially for sensors supplied by Chinese manufacturers and in 
user-assembled devices from those parts. In case of professional use, it is necessary to distinguish between the use of sensor system / network for informative or identification purposes and the reference measurements of the national air quality monitoring network.

Research focused on the social level of air quality sensor devices availability to the general public was recently conducted. It revealed that laymen directly involved in air quality data collection are more interested not only in air quality in general, but also in the fields of evaluation of these data and presentation of results. In particular, they alter daily routines and activities more effectively when compared to people receiving ordinary public information, especially in periods of lower air quality [66].

As shown in the growth of publication numbers, sensor technology is undergoing great development. The use is already widespread in the field of air quality measurement. In the current state of the technology and the near future, the results of sensor measurements will definitely not be applicable for air quality management according to legislation. Rather than use in reference measurements, further development of complementary applications should be expected, such as deployments in remote areas or developing countries and expansion of widespread multi-nodal sensor networks.

\section{Acknowledgement}

Authors thank for financial support the OP RDE project No. CZ.02.1.01/0.0/0.0/18_069/0010049 "Research on the identification of combustion of unsuitable fuels and systems of self-diagnostics of boilers combustion solid fuels for domestic heating" (Ministry of Education, the Youth and Sports of the Czech Republic in the framework of the National Sustainability by ERDF/ESF).

\section{References}

[1] Barkjohn KK, Bergin MH, Norris C, Schauer JJ, Zhang Y, Black M, et al. Aerosol Air Qual Res. 2019;20:297-313. DOI: 10.4209/aaqr.2018.11.0394.

[2] Liu MK. Barkjohn K, Norris CJ, Schauer J, Zhang J, Zhang Y, et al. Environ Sci: Processes Impacts. 2020;22:131-143. DOI: 10.1039/C9EM00377K.

[3] Amegah AK. Environ Pollut. 2018;241:1132-7. DOI: 10.1016/j.envpol.2018.06.044.

[4] Park J, Lee PS-H. Forests. 2020;11:1060, DOI: 10.3390/f11101060.

[5] Siddiqui AR, Lee K, Bennett D, Yang X, Brown KH, Bhutta ZA, et al. Indoor Air. 2009;19:75-82. DOI: 10.1111/j.1600-0668.2008.00563.x.

[6] Cross ES, Williams LR, Lewis DK, Magoon GR, Onasch TB, Kaminsky ML, et al. Atmos Measurement Techniq. 2017;10:3575-88. DOI: 10.5194/amt-10-3575-2017.

[7] Mead MI, Popoola O, Stewart G, Landshoff P, Calleja M, Hayes M, et al. Atmos Environ. 2013;70:186-203, DOI: 10.1016/j.atmosenv.2012.11.060.

[8] Mukherjee A, Brown SG, McCarthy MC, Pavlovic NR, Stanton LG, Snyder JL, et al. Sensors. 2019;19:4701. DOI: 10.3390/s19214701.

[9] Pérez-Rial D, López-Mahía P, Muniategui-Lorenzo S, Prada-Rodríguez D. J Environ Monit. 2009;11:1216-25. DOI: 10.1039/B819370C.

[10] Zikova N, Masiol M, Chalupa DC, Rich DQ, Ferro AR, Hopke PK, Sensors. 2017;17:1922. DOI: $10.3390 / \mathrm{s} 17081922$

[11] Zhan Y, Johnson K, Norris C, Shafer MM, Bergin MH, Zhang Y, et al. Sci Total Environ. 2018;626:507-18. DOI: 10.1016/j.scitotenv.2018.01.024.

[12] Costa-Gómez I, Bañón D, Moreno-Grau S, Revuelta R, Elvira-Rendueles B, Moreno J. Air Qual Atmos Health. 2020;13:15-23. DOI: 10.1007/s11869-019-00768-8.

[13] Air quality sensors field evaluation. Available from: http:/www.aqmd.gov/aq-spec/evaluations/field. Accessed 30.11.2020.

[14] EOC Inc. NDIR Gas Sensor Modules. Available from: https://www.eoc-inc.com/ndir-gas-sensor-modules/. Accessed 1.12.2020. 
[15] Portable Gas Detector, Single \& Multi Gas monitor. SafetyGas. Available from: https://en.safetygas.com/gas-detection/portable-gas-detector. Accessed 1.12.2020.

[16] Application Notes. Alphasense. Available from: http://www.alphasense.com/index.php/safety/applicationnotes/. Accessed 1.12.2020.

[17] Environmental sensors Co. Hand held models. Available from: http://www.environmentalsensors.com/ y-series-models.html. Accessed 2.12.2020.

[18] Szulczyński B, Gębicki J. Environments. 2017;4:21. DOI: 10.3390/environments4010021.

[19] Dey A, Materials Sci Eng: B. 2018;229:206-17. DOI: 10.1016/j.mseb.2017.12.036.

[20] Ivanovskaya M, Gurlo A, Bogdanov P. Sensors Actuators B: Chemical. 2001;77:264-7. DOI: 10.1016/S0925-4005(01)00708-0.

[21] Afzal A, Cioffi N, Sabbatini L, Torsi L. Sensors Actuators B: Chemical. 2012;171-172:25-42. DOI: 10.1016/j.snb.2012.05.026.

[22] Becker T, Tomasi L, Bosch-v.Braunmühl C, Müller G, Sberveglieri G, Fagli G, et al. Sensors Actuators A: Physical 1999;74:229-32. DOI: 10.1016/S0924-4247(98)00301-X.

[23] Cantalini C, Valentini L, Lozzi L, Armentano I, Kenny JM, Santucci S. Sensors Actuators B: Chemical. 2003;93:333-7. DOI: 10.1016/S0925-4005(03)00224-7.

[24] Alphasense Ltd. Technical Specification - PID A12 Photo Ionisation Detector. Available from: http://www.alphasense.com/WEB1213/wp-content/uploads/2019/08/PID-A12-1.pdf. Accessed 16.05.2020.

[25] Poole CF. J Chromatography A. 2015;1421:137-53. DOI: 10.1016/j.chroma.2015.02.061.

[26] MSA Safety, Data Sheet-0800-32. Available from: http://media.msanet.com/NA/USA/PortableInstruments/ CombinationInstrumentsandCombustibleGasIndicators/SiriusMultigasDetector/0800-32.pdf. Accessed 30.11.2020.

[27] Coelho Rezende G, Le Calvé S, Brandner JJ, Newport D. Sensors Actuators B: Chemical. 2019;287:86-94. DOI: 10.1016/j.snb.2019.01.072.

[28] Ripoll A, Viana M, Padrosa M, Querol X, Minutolo A, Hou KM, et al. Sci Total Environ. 2019;651:1166-79. DOI: 10.1016/j.scitotenv.2018.09.257.

[29] Brynda P, Kopřiva J, Horák M. Procedia Eng. 2015;120:902-7. DOI: 10.1016/j.proeng.2015.08.781.

[30] Malings C, Tanzer R, Hauryliuk A, Saha PK, Robinson AL, Presto AA, et al. Aerosol Sci Technol. 2020;54:160-74. DOI: 10.1080/02786826.2019.1623863.

[31] Jiao W, Hagler G, Williams R, Sharpe R, Brown R, Garver D, et al. Atmospheric Measurement Techniques. 2016;9:5281-92. DOI: 10.5194/amt-9-5281-2016.

[32] Air Quality Egg - Science is Collaboration. Available from: https://airqualityegg.com/home. Accessed 31.05.2020.

[33] Empowering the World to Breathe Cleaner Air. IQAir. Available from: https://www.iqair.com/. Accessed 31.05.2020.

[34] luftdaten.info. Available from: https://luftdaten.info/. Accessed 1.06.2020.

[35] Ion Science, Gas and Leak Detectors. Available from: https://www.ionscience.com/gas-and-leak-detectors/. Accessed 30.11.2020.

[36] Product Range - Ion Science. Available from: https://www.ionscience.com/product-range/. Accessed 31.05.2020.

[37] Khedo KK, Perseedoss R, Mungur A. IJWMN. 2010;2:31-45. DOI: 10.5121/ijwmn.2010.2203.

[38] Tsujita W, Yoshino A, Ishida H, Moriizumi T. Sensors Actuators B: Chemical. 2005;110:304-11. DOI: 10.1016/j.snb.2005.02.008.

[39] Bettair Cities SL. Report of deployment of air quality monitor in the city of Girona. Available from: https://seu.girona.cat/portal/dades/transparencia/docs/2019_qualitat-aire-Bettair.pdf.

[40] Bettair Cities SL. Achieving high accuracy air quality measurements with Bettair ${ }^{\circledR}$ static monitors. Available from: https://nanosen-aqm.sciencesconf.org/data/pages/O5_4_Santiago.pdf.

[41] Spinelle L, Gerboles M, Villani MG, Aleixandre M, Bonavitacola F. Sensors Actuators B: Chemical. 2015;215:249-57. DOI: 10.1016/j.snb.2015.03.031.

[42] Spinelle L, Gerboles M, Villani MG, Aleixandre M, Bonavitacola F. Sensors Actuators B: Chemical. 2017;238:706-15. DOI: 10.1016/j.snb.2016.07.036.

[43] Bauerová P, Šindelářová A, Rychlík Š, Novák Z, Keder J. Atmosphere. 2020;11:492. DOI: 10.3390/atmos 11050492 .

[44] Levy Zamora M, Xiong F, Gentner D, Kerkez B, Kohrman-Glaser J, Koehler K. Environ Sci Technol. 2019;53:838-49. DOI: 10.1021/acs.est.8b05174.

[45] Zikova N, Hopke PK, Ferro AR. J Aerosol Sci. 2017;105:24-34. DOI: 10.1016/j.jaerosci.2016.11.010.

[46] Jayaratne R, Liu X, Thai P, Dunbabin M, Morawska L. Atmospheric Measurement Techniques. 2018;11:4883-90. DOI: 10.5194/amt-11-4883-2018. 
[47] Zheng T, Bergin MH, Johnson KK, Tripathi SN, Shirodkar S, Landis MS, et al. Atmospheric Measurement Techniques. 2018;11:4823-46. DOI: 10.5194/amt-11-4823-2018.

[48] Castell N, Dauge FR, Schneider P, Vogt M, Lerner U, Fishbain B, et al. Environ Int. 2017;99:293-302. DOI: 10.1016/j.envint.2016.12.007.

[49] Gameli Hodoli C, Coulon F, Mead MI. Heliyon. 2020;6:e04206. DOI: 10.1016/j.heliyon.2020.e04206.

[50] Wang Y, Li J, Jing H, Zhang Q, Jiang J, Biswas P. Aerosol Sci Technol. 2015;49:1063-77. DOI: 10.1080/02786826.2015.1100710.

[51] Badura M, Batog P, Drzeniecka-Osiadacz A, Modzel P. SN Appl Sci. 2019;1:622. DOI: 10.1007/s42452-019-0630-1.

[52] Shao W, Zhang H, Zhou H, Sensors. 2017;17:1033. DOI: 10.3390/s17051033.

[53] Clougherty JE, Kheirbek I, Eisl HM, Ross Z, Pezeshki G, Gorczynski JE, et al. J Expo Sci Environ Epidemiol. 2013;23:232-40. DOI: 10.1038/jes.2012.125.

[54] Spinelle L, Aleixandre M, Gerboles M. Protocol of evaluation and calibration of low-cost gas sensors for the monitoring of air pollution. EUR 26112. Luxembourg (Luxembourg): Publications Office of the European Union; 2013. JRC83791. DOI: 10.2788/9916.

[55] Honeywell, MultiRAE Benzene. Available from: https://safety.honeywell.com/content/his/us/en/home/ products/by-category/gas-flame-detection/portables/multirae-benzene.html. Accessed 1.12.2020.

[56] Ion Science: gas detectors \& PID sensors. Available from: https://www.ionscience.com/. Accessed 1.06.2020.

[57] Stark instruments. Gas Detector. Available from: http://www.starkinstrument.com/e_products/Gas-Detector6-29.html. Accessed 1.12.2020.

[58] Driscoll JN. J Chromatogr Sci. 1982;20:91-4. DOI: 10.1093/chromsci/20.2.91.

[59] Pang X, Nan H, Zhong J, Ye D, Shaw MD, Lewis AC. Sci Total Environ. 2019:664:771-9. DOI: 10.1016/j.scitotenv.2019.01.348.

[60] Portable VOC analyzer - Gas chromatograph - X-PID 9500. Available from: https://en.safetygas.com/portable-voc-analyzer-xpid-9500-gas-chromatograph. Accessed 3.12.2020.

[61] FROG-5000 Portable Gas Chromatograph GC PID. Available from: https://www.defiant-tech.com/frogportable-gas-chromatograph-gc/. Accessed 3.12.2020.

[62] Rezende GC, Le Calvé S, Brandner JJ, Newport D. Micromachines. 2019;10:228. DOI: $10.3390 / \mathrm{mi} 10040228$.

[63] Gupta P, Doraiswamy P, Levy R, Pikelnaya O, Maibach J, Feenstra B, et al. GeoHealth. 2018;2:172-81. DOI: $10.1029 / 2018 \mathrm{GH} 000136$.

[64] Levy RC, Mattoo S, Munchak LA, Remer LA, Sayer AM, Patadia F, et al. Atmospheric Measurement Techniques. 2013;6:2989-3034. DOI: 10.5194/amt-6-2989-2013.

[65] Sowden M, Blake D, Atmospheric Environment. 2020;241:117620. DOI: 10.1016/j.atmosenv.2020.117620.

[66] Hubbell BJ, Kaufman A, Rivers L, Schulte K, Hagler G, Clougherty J, et al. Sci Total Environ. 2018;621: 886-94. DOI: 10.1016/j.scitotenv.2017.11.275. 